\title{
Modifikasi Perencanaan Gedung Rumah Sakit Umum Daerah (RSUD) Koja Jakarta Dengan Metode Pracetak
}

\author{
Trie Sony Kusumowibowo dan Endah Wahyuni \\ Jurusan Teknik Sipil, Fakultas Teknik Sipil dan Perencanaan, Institut Teknologi Sepuluh Nopember (ITS) \\ Jl. Arief Rahman Hakim, Surabaya 60111 Indonesia \\ E-mail: endah@ce.its.ac.id
}

\begin{abstract}
Abstrak - Metode pracetak saat ini telah banyak digunakan dalam pembangunan konstruksi sipil. Hal ini terjadi karena beton pracetak memiliki beberapa kelebihan dibandingkan beton yang dicor di tempat (cast in situ). Kelebihannya antara lain yaitu proses pembuatannya yang tidak bergantung cuaca, tidak memerlukan banyak bekisting, waktu pengerjaan yang lebih singkat, kontrol kualitas beton lebih terjamin serta menurut penelitian terbaru beton pracetak juga ramah lingkungan.

Tujuan dari Penelitian ini adalah menghasilkan perencanaan struktur gedung RSUD Koja Jakarta dengan metode pracetak. Merencanakan detailing penulangan dan sambungan pada elemen beton pracetak. Merencanakan struktur basement dan pondasi yang menopang gedung. Dan merancang gambar teknik dari hasil modifikasi gedung ini.

Gedung RSUD Koja Jakarta ini dirancang ulang menggunakan metode pracetak pada bagian balok dan pelat. Standar yang digunakan dalam perencanaan ini adalah perencanaan struktural menggunakan tata cara perhitungan struktur beton untuk bangunan gedung (SNI 2847:2013) [5], untuk menghitung pembebanan gravitasi menggunakan PPIUG 1983 dan tata cara perhitungan pembebanan untuk gedung (SNI 1727:2013), dan pembebanan gempa dihitung menggunakan tata cara perencanaan ketahanan gempa (SNI 1726:2012) [6]. Perencanaan gedung ini menggunakan sistem ganda (dual system), beban lateral $25 \%$ dipikul oleh rangka dan $75 \%$ dipikul oleh dinding geser.

Hasil dari modifikasi gedung RSUD Koja Jakarta ini meliputi ukuran balok induk 50/70, ukuran balok anak 30/50, dan 2 macam ukuran kolom yaitu lantai $1-1090 \times 90 \mathrm{~cm}$ dan lantai 11-20 $80 \times 80 \mathrm{~cm}$. Modifikasi gedung ini juga menggunakan shearwall dengan tebal $40 \mathrm{~cm}$ yang berfungsi menahan $75 \%$ beban lateral. Sambungan antar elemen bracetak menggunakan sambungan basah dan konsol pendek.
\end{abstract}

Kata Kunci - Beton Bertulang, Gedung RSUD Koja, Modifikasi Perencanaan, Pracetak,

\section{PENDAHULUAN}

\section{A. Latar Belakang}

$\mathrm{D}^{\mathrm{i}}$ Indonesia, hingga saat ini, telah banyak aplikasi teknologi beton pracetak pada banyak jenis konstruksi dengan didukung oleh sekitar 16 perusahaan spesialis beton pracetak, atau lebih dikenal dengan sebutan precaster [1]. Hal ini dilakukan karena semakin besarnya tuntutan pelaksanaan pekerjaan konstruksi yang efisien dan cepat namun harus tetap menjaga ketepatan dan kualitas beton. Metode pracetak memiliki beberapa kelebihan dibandingkan metode cor setempat (cast in site). Kelebihan tersebut antara lain adalah metode pracetak tidak membutuhkan tempat penyimpanan material yang luas, waktu pengerjaan yang relatif singkat, kontrol kualitas beton lebih terjamin, tidak memerlukan treatment atau perlakukan khusus, tidak membutuhkan terlalu banyak bekisting dan penopang bekisting, serta praktis dan cepat dalam pelaksanaanya[2].

Weyantadji, et.al., menyatakan bahwa dalam pemasangan komponen pracetak ada tiga tahap yaitu penulangan saat pengangkatan, penulangan saat beton overtopping belum kering, dan penulangan saat beton overtopping sudah kering[3]. Menurut Wulfram I. Ervianto bila dibandingkan dengan beton cast-in place, beton pracetak mempunyai kualitas yang lebih baik. Hal ini karena hal - hal sebagai berikut: (a) proses produksi dilaksanakan dengan menggunakan mesin, (b) kondisi pabrik yang relative konstan, (c) pengawasan yang lebih cermat, (d) kondisi dari lingkungan kerja yang lebih baik[4].

Berdasarkan hal di atas, maka dalam penelitian ini, penulis melakukan modifikasi perencanaan Gedung Rumah Sakit Umum Daerah (RSUD) Koja Jakarta. Gedung RSUD Koja Jakarta ini memiliki 16 (enam belas) lantai dan menggunakan metode cor di tempat (in site) dalam pemilihan metode konstruksinya.

\section{B. Perumusan Masalah}

\section{Masalah Utama:}

Bagaimana merencanakan gedung RSUD Koja Jakarta dengan metode pracetak?

Rincian Masalah:

1. Bagaimana preliminary design elemen - elemen dari beton pracetak?

2. Bagaimana pembebanan dari bangunan tersebut?

3. Bagaimana analisis struktur dari bangunan tersebut?

4. Bagaimana merancang dimensi elemen - elemen dari beton pracetak?

5. Bagaimana merancang detailing sambungan pada komponen pracetak?

6. Bagaimana menuangkan hasil perhitungan dan perancangan ke dalam gambar teknik?

\section{Tujuan Penelitian}

1. Merancang preliminary design elemen - elemen dari beton pracetak

2. Menghitung pembebanan dari bangunan tersebut

3. Menganalisis struktur dari bangunan tersebut

4. Merancang dimensi elemen - elemen dari beton pracetak

5. Merancang detail sambungan pada komponen pracetak

6. Menuangkan hasil perhitungan dan perancangan ke dalam gambar teknik

\section{Batasan Masalah}

1. Tidak memperhitungkan manajemen konstruksi (biaya, waktu)

2. Penggunaan pracetak hanya pada balok dan pelat saja 


\section{E. Manfaat}

Dengan adanya penulisan Penelitian ini diharapkan dapat memberikan wawasan khususnya kepada penulis tentang metode pracetak.

\section{URAIAN PERENCANAAN}

\section{A. Diagram Alir Perencanaan}

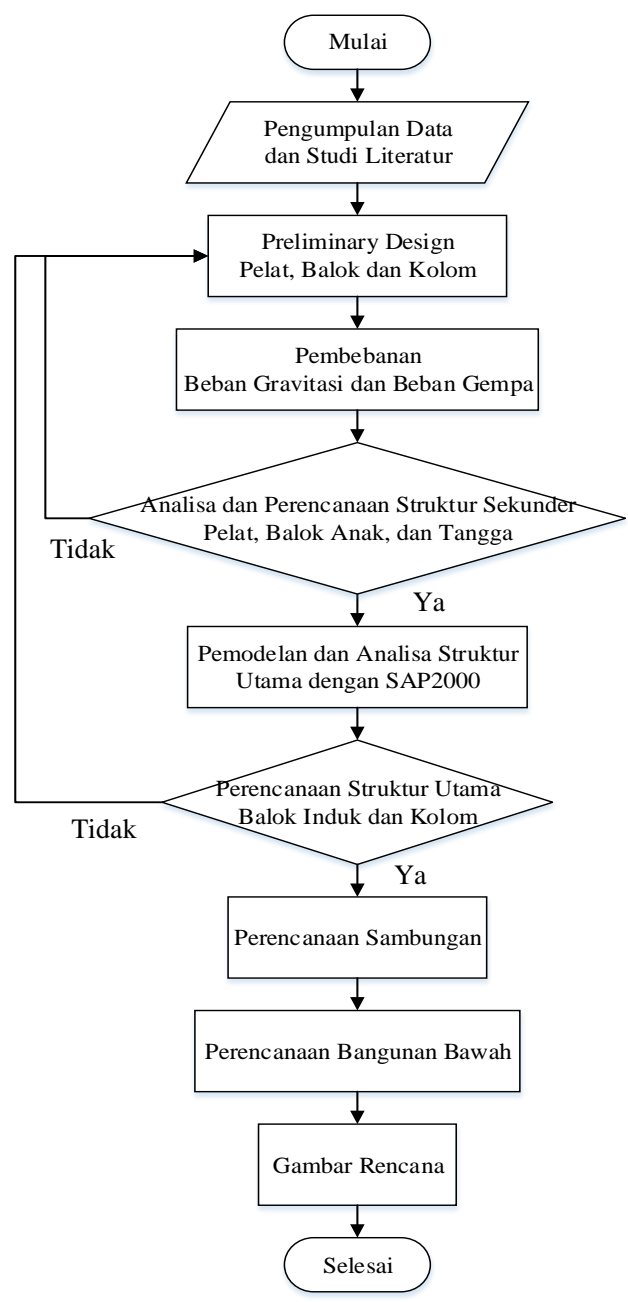

Gambar 1. Diagram alir penyelesaian penelitian

\section{B. Modifikasi dan Kriteria Pemilihan Struktur}

Data - data setelah modifikasi:

- Nama gedung : Rumah Sakit Umum Daerah Koja

\section{Jakarta}

- Lokasi : Jakarta

- Fungsi : Rumah Sakit

- Jumlah lantai : 20 lantai dan 1 basement

- Tinggi bangunan : \pm 80 meter

- Struktur utama : Beton pracetak (non prategang)

- Mutu beton (f'c) : $30 \mathrm{MPa}$

- Mutu baja (fy) : $400 \mathrm{MPa}$

\section{Preliminary Design}

Preliminary design merupakan tahapan perhitungan dalam perancangan untuk merencanakan dimensi awal dari suatu elemen struktur.

1. Preliminary design dimensi balok induk, balok anak, dan balok lift sesuai dengan SNI 2847:2013 pasal 9.5.2.1 tabel 9.5 (a)
2. Dimensi (tebal) pelat ditentukan menurut peraturan SNI 2847:2013 pasal 9.5.3.3 tabel 9.5 (c)

3. Preliminary design kolom sesuai dengan SNI 2847:2013 pasal 10.3.6[5]

\section{HASIL DAN PEMBAHASAN}

A. Preliminary Design

Untuk desain awal bangunan dapat dilihat pada Gambar 2.

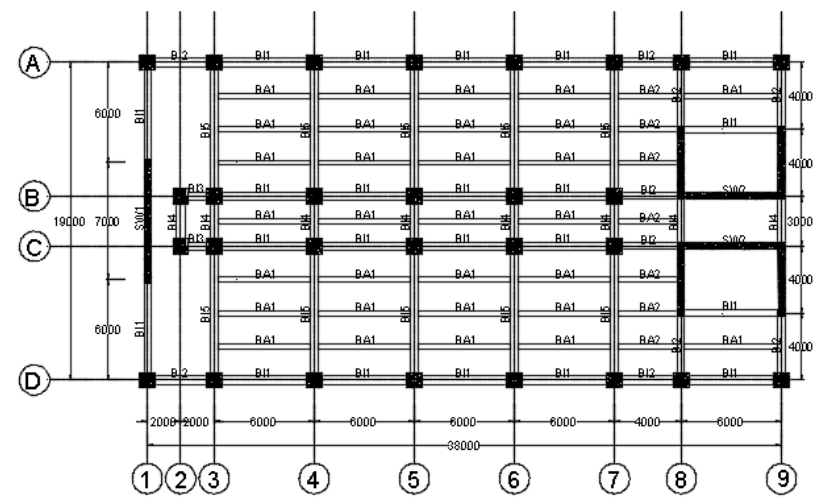

Gambar 2. Denah balok dan kolom

\section{Dimensi Balok}

Sesuai dengan SNI 2847:2013 pasal 9.5.2.1 tabel 9.5 (a) untuk dimensi balok yang direkapitulasi pada Tabel 1 dan Tabel 2.

Tabel 1.

Rekapitulasi Dimensi Balok Induk

\begin{tabular}{|c|c|c|c|c|c|}
\hline $\begin{array}{l}\text { Kode } \\
\text { Balok } \\
\text { Induk }\end{array}$ & $\begin{array}{c}\text { Bentang } \\
\left(\mathbf{L}_{\mathbf{b}}\right) \\
\mathrm{cm}\end{array}$ & $\begin{array}{r}\mathbf{h}_{\text {min }} \\
\mathbf{c m}\end{array}$ & $\begin{array}{c}\mathbf{h}_{\text {pakai }} \\
\text { cm }\end{array}$ & $\begin{array}{c}\mathbf{b}_{\text {pakai }} \\
\mathrm{cm}\end{array}$ & $\begin{array}{c}\text { Dimensi } \\
\mathrm{cm}\end{array}$ \\
\hline BI1 & 600 & 36,4 & 70 & 50 & $50 / 70$ \\
\hline $\mathrm{BI} 2$ & 400 & 24,2 & 70 & 50 & $50 / 70$ \\
\hline $\mathrm{BI} 3$ & 200 & 12,1 & 70 & 50 & $50 / 70$ \\
\hline BI4 & 300 & 18,2 & 70 & 50 & $50 / 70$ \\
\hline BI5 & 800 & 48,5 & 70 & 50 & $50 / 70$ \\
\hline
\end{tabular}

Tabel 2.

Rekapitulasi Dimensi Balok Anak

\begin{tabular}{|c|c|c|c|c|c|}
\hline $\begin{array}{l}\text { Kode } \\
\text { Balok } \\
\text { Anak }\end{array}$ & $\begin{array}{c}\text { Bentang } \\
\left(\mathbf{L}_{\mathbf{b}}\right) \\
\text { cm }\end{array}$ & $\begin{array}{l}h_{\text {min }} \\
\text { cm }\end{array}$ & $\begin{array}{c}h_{\text {pakai }} \\
\text { cm }\end{array}$ & $\begin{array}{c}b_{\text {pakai }} \\
\mathrm{cm}\end{array}$ & $\begin{array}{c}\text { Dimensi } \\
\mathrm{cm}\end{array}$ \\
\hline BA1 & 600 & 28,5 & 50 & 30 & $30 / 50$ \\
\hline BA2 & 400 & 19,0 & 50 & 30 & $30 / 50$ \\
\hline
\end{tabular}

\section{Dimensi Pelat}

Dari hasil perhitungan diperoleh tebal pelat yang dapat dilihat pada Tabel 3

Tabel 3.

Rekapitulasi Tebal Pelat

\begin{tabular}{ccccc}
\hline \hline Tipe Pelat & $\begin{array}{c}\text { Lx } \\
\text { cm }\end{array}$ & $\begin{array}{c}\text { Ly } \\
\mathbf{c m}\end{array}$ & $\begin{array}{c}\text { Jenis } \\
\text { Pelat }\end{array}$ & $\begin{array}{c}\mathbf{h}_{\text {pakai }} \\
\mathbf{c m}\end{array}$ \\
\hline S1 & 200 & 600 & 1 Arah & 15 \\
S2 & 150 & 600 & 1 Arah & 15 \\
S3 & 200 & 400 & 1 Arah & 15 \\
S4 & 150 & 400 & 1 Arah & 15 \\
\hline \hline
\end{tabular}

\section{Dimensi Kolom}

Menurut SNI 2847:2013 pasal 9.3.2.2 (b) untuk komponen struktur beton bertulang lainnya faktor reduksi, $\Phi=0,65$. Mutu beton $=30 \mathrm{MPa}=3 \mathrm{~kg} / \mathrm{mm}^{2}$

$A=\frac{W}{\phi f^{\prime c}}=\frac{1124582}{0,65 \times 3}=576708,9 \mathrm{~mm}^{2}$

Dengan asumsi kolom berbentuk persegi maka:

$h=\sqrt{A}=\sqrt{576708,9}=759,41 \mathrm{~mm} \approx 76 \mathrm{~cm}$

Maka digunakan dimensi kolom 90/90 


\section{Dimensi Dinding Geser}

Berdasarkan peraturan SNI 2847:2013 pasal 14.5.3.1 ketebalan dinding pendukung tidak boleh kurang dari 1/25 tinggi, maka:

$T \geq H / 25 \quad \frac{400}{25}=16 \mathrm{~cm}$

$T \geq L / 25 \quad \frac{800}{25}=32 \mathrm{~cm}$

Maka digunakan tebal dinding geser $40 \mathrm{~cm}$

\section{Desain Tangga}

Data perencanaan yang diperlukan untuk merencanakan konstruksi tangga adalah sebagai berikut:
- Mutu beton (f’c)

- Mutu baja (fy)

- Tinggi antar lantai

- Panjang bordes

- Lebar bordes

- Lebar tangga

- Tebal pelat tangga

- Tebal pelat bordes

- Tinggi injakan

- Lebar injakan

- Jumlah tanjakan

- Jumlah injakan

- Jumlah tanjakan ke bordes $=30 \mathrm{MPa}$ $=400 \mathrm{MPa}$

$=4 \mathrm{~m}$

$=3 \mathrm{~m}$

$=1,5 \mathrm{~m}$

$=1,5 \mathrm{~m}$

$=20 \mathrm{~cm}$

$=20 \mathrm{~cm}$

$=20 \mathrm{~cm}$

$=25 \mathrm{~cm}$

$=20$ buah

$=20$ buah

$=10$ buah

- Jumlah tanjakan dari bordes ke lantai 2=10 buah

- Elevasi bordes

$=200 \mathrm{~cm}$

- Kemiringan tangga

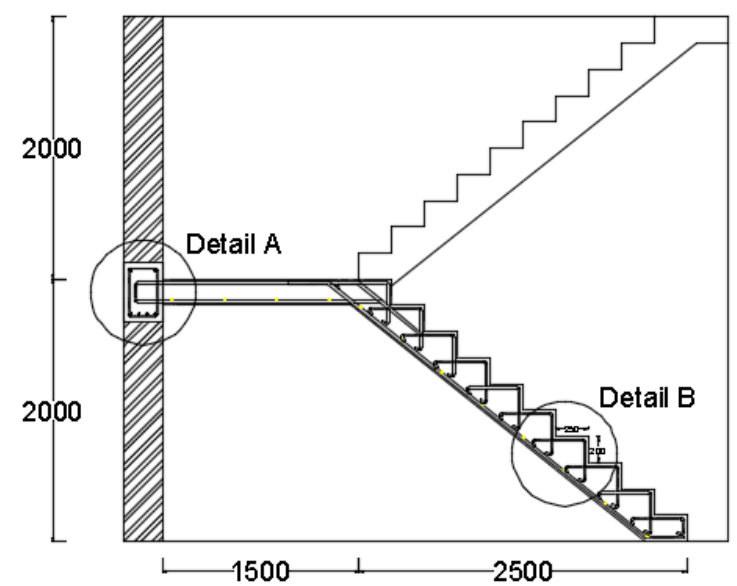

Gambar 3. Perencanaan Tangga

\section{Desain Ramp}

Data perencanaan yang diperlukan untuk merencanakan konstruksi ramp adalah sebagai berikut:

- Mutu beton (f'c)

- Mutu baja (fy)

- Tinggi antar lantai

- Panjang bordes

- Lebar bordes

- Lebar ramp

- Tebal pelat ramp

- Tebal pelat bordes

- Elevasi bordes

- Kemiringan tangga

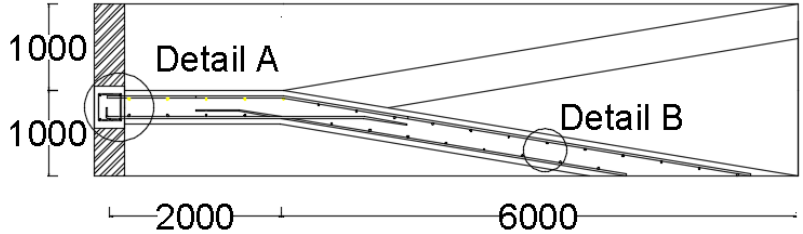

Gambar 4. Perencanaan Ramp

\section{B. Desain Struktur Sekunder}

1. Penulangan Pelat Lantai

Kombinasi pembebanan yang digunakan:

$\mathrm{Qu}=1,2 \mathrm{DL}+1,6 \mathrm{LL}$

Sehingga diperoleh hasil penulangan pelat sebagai berikut Tabel 4. Penulangan Pelat

\begin{tabular}{|c|c|c|c|c|c|c|}
\hline \multirow[b]{2}{*}{$\begin{array}{l}\text { Tipe } \\
\text { Pelat }\end{array}$} & \multicolumn{2}{|c|}{ Ukuran Pelat } & \multicolumn{2}{|c|}{ Tulangan Terpasang } & \multirow[b]{2}{*}{ Stud } & \multirow[b]{2}{*}{$\begin{array}{c}\text { Tulangan } \\
\text { Angkat }\end{array}$} \\
\hline & $\begin{array}{c}\text { Panjang } \\
\text { (m) }\end{array}$ & $\begin{array}{c}\text { Lebar } \\
\text { (m) }\end{array}$ & $\begin{array}{c}\text { Tulangan } \\
\text { Utama }\end{array}$ & $\begin{array}{l}\text { Tulangan } \\
\text { Pembagi }\end{array}$ & & \\
\hline S1 & 6 & 2 & D10-150 & D10-250 & D10-150 & D10 \\
\hline S2 & 4 & 1,5 & D10-150 & D10-250 & D10-150 & D10 \\
\hline S3 & 6 & 2 & D10-150 & D10-250 & D10-150 & D10 \\
\hline S4 & 4 & 1,5 & D10-150 & D10-250 & D10-150 & D10 \\
\hline
\end{tabular}

Gambar 5. Detail Penulangan Pelat

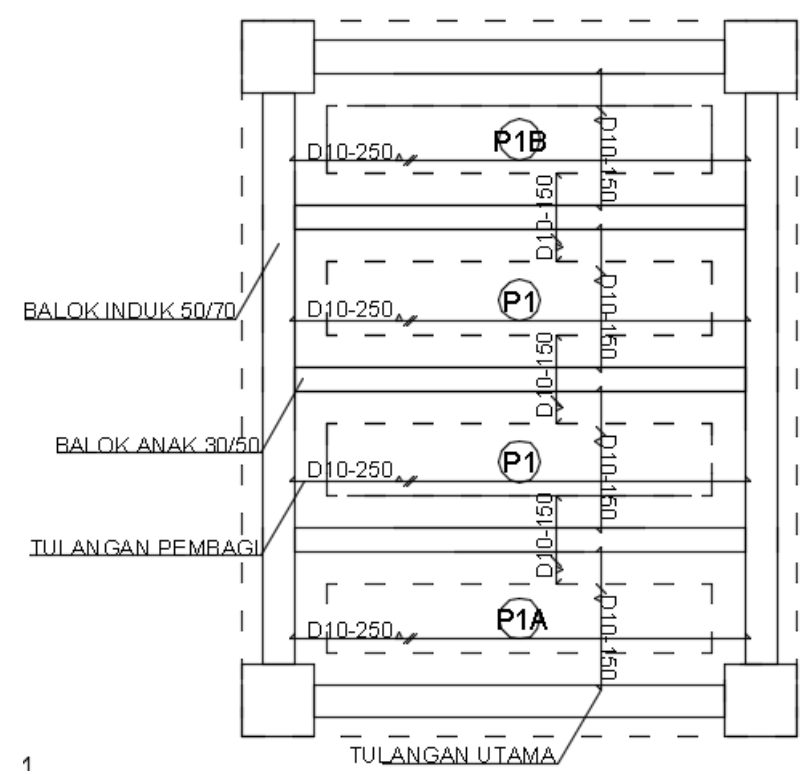

2. Perencanaan Balok Anak

- Balok anak (30/50)

Dari hasil perhitungan diperoleh kebutuhan tulangan tumpuan dan tulangan lapangan yang dapat dilihat pada Tabel 5.

Tabel 5.

Penulangan Balok Anak

\begin{tabular}{cccccc}
\hline \hline $\begin{array}{c}\text { Kode } \\
\text { Balok } \\
\text { Anak }\end{array}$ & $\begin{array}{c}\text { Bentang } \\
\text { (Lb) }\end{array}$ & \multicolumn{2}{c}{ Tulangan Terpasang } \\
m & $\begin{array}{c}\text { Tulangan } \\
\text { Tumpuan }\end{array}$ & $\begin{array}{c}\text { Tulangan } \\
\text { Lapangan }\end{array}$ & $\begin{array}{c}\text { Tulangan } \\
\text { Sengkang }\end{array}$ & $\begin{array}{c}\text { Tulangan } \\
\text { Angkat }\end{array}$ \\
\hline BA1 & 6 & $2 \mathrm{D} 22$ & $2 \mathrm{D} 22$ & $\Phi 10-100$ & $\Phi 10$ \\
BA2 & 4 & $2 \mathrm{D} 22$ & $2 \mathrm{D} 22$ & $\Phi 10-100$ & $\Phi 10$ \\
\hline \hline
\end{tabular}




\section{Desain Tangga}

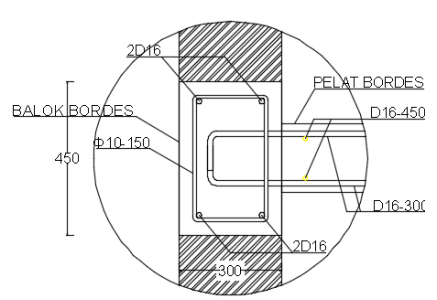

(a)

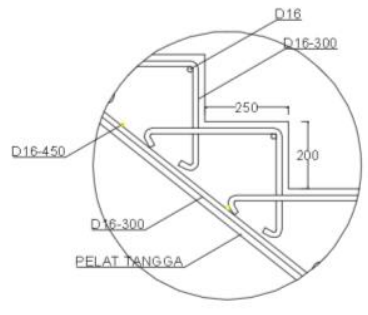

(b)
Gambar 6. Penulangan Tangga (a) balok bordes (b) pelat tangga

a. Penulangan Pelat Tangga

Data perencanaan:

- $\mathrm{f}^{\prime} \mathrm{c}=30 \mathrm{MPa}$

- $\mathrm{fy}=400 \mathrm{MPa}$

Digunakan tulangan lentur arah X D16-300 mm

Digunakan tulangan lentur arah Y D16-450 mm

b. Penulangan Pelat Bordes

Data perencanaan:

- $\mathrm{f}^{\prime} \mathrm{c}=30 \mathrm{MPa}$

- $\mathrm{fy}=400 \mathrm{MPa}$

Digunakan tulangan lentur arah X D16-300 mm Digunakan tulangan lentur arah Y D16-450 mm

c. Penulangan Balok Bordes

Dimensi balok bordes dipakai 30/45 cm

Digunakan tulangan tumpuan 2D16

Digunakan tulangan lapangan 3D16

Digunakan tulangan sengkang Ø10-150 mm

\section{Desain Ramp}

a. Penulangan Pelat Ramp

Data perencanaan:

- $\mathrm{f}^{\prime} \mathrm{c}=30 \mathrm{MPa}$

- $\mathrm{fy}=400 \mathrm{MPa}$

Digunakan tulangan lentur arah X D22-250 mm

Digunakan tulangan lentur arah Y D22-450 mm

b. Penulangan Pelat Bordes

Data perencanaan:

- $\mathrm{f}^{\prime} \mathrm{c}=30 \mathrm{MPa}$

- fy $=400 \mathrm{MPa}$

Digunakan tulangan lentur arah X D22-300 mm Digunakan tulangan lentur arah Y D22-450 mm

c. Penulangan Balok Bordes

Dimensi balok bordes dipakai $35 / 50 \mathrm{~cm}$

Digunakan tulangan tumpuan 3D16

Digunakan tulangan lapangan 4D16

Digunakan tulangan sengkang Ø10-150 mm

\section{Perhitungan Balok Lift}

- Data perencanaan (Hospital Elevator)

Pada bangunan ini digunakan lift yang diproduksi oleh Hyundai Elevator dengan data - data sebagai berikut:

Tipe lift : Standard Type B1750-2S30-60

Kapasitas : $1750 \mathrm{~kg}$

Beban reaksi ruang mesin:

$$
\text { - } \quad \mathrm{R} 1=11500 \mathrm{~kg}
$$$$
\text { - } \quad \mathrm{R} 2=9500 \mathrm{~kg}
$$

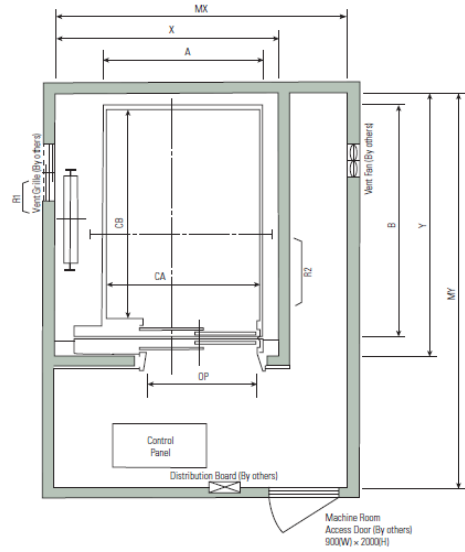

Gambar 7. Denah Lift

Diperoleh dimensi balok:

- Balok penggantung lift (30/50)

- Balok penumpu (30/50)

C. Pembebanan dan Analisis Gaya Gempa

1. Kombinasi Beban Berfaktor

Kombinasi - kombinasi beban yang digunakan adalah sebagai berikut:

- $1,4 \mathrm{DL}$

- $1,2 \mathrm{DL}+1,6 \mathrm{LL}$

- $1,2 \mathrm{DL}+1,0 \mathrm{LL}+1,0 \mathrm{Ex}$

- $1,2 \mathrm{DL}+1,0 \mathrm{LL}+1,0 \mathrm{Ey}$

- $1,0 \mathrm{DL}+1,0 \mathrm{LL}$

- $0,9 \mathrm{DL}+1,0 \mathrm{Ex}$

- $0,9 \mathrm{DL}+1,0 \mathrm{Ey}$

\section{Data Perencanaan}

Data - data analisis gempa yang akan digunakan adalah sebagai berikut:

- Kelas Situs = SB

- Kategori Risiko = IV

- Faktor keutamaan $=1,5$

- Ss $\quad=0,686 \mathrm{~g}$

- $\mathrm{S} 1 \quad=0,3 \mathrm{~g}$

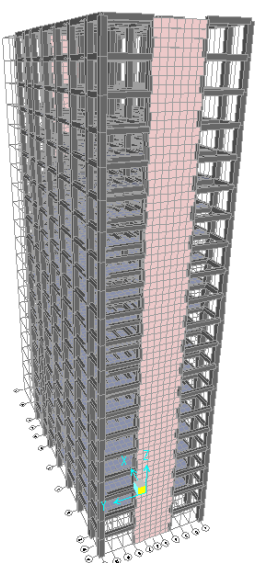

Gambar 8. Permodelan 3D Gedung

\section{Kontrol Sistem Ganda}

Untuk sistem ganda, rangka pemikul momen harus mampu menahan paling sedikit 25 persen gaya gempa desain. Tahanan gaya gempa total harus disediakan oleh kombinasi rangka pemikul momen dan dinding geser atau rangka bresing, dengan distribusi yang proporsional terhadap kekakuannya[5]. 
Tabel 6. Persentase Gaya Geser yang Mampu Dipikul Sistem Struktur

\begin{tabular}{ccccc}
\hline \hline $\begin{array}{c}\text { Pemikul Gaya } \\
\text { Geser }\end{array}$ & Arah X (N) & \% & Arah Y (N) & $\%$ \\
\hline Dinding Geser & 8513337.9 & $72 \%$ & 9289649.93 & $69 \%$ \\
Sistem Rangka & 3366184.1 & $28 \%$ & 4128673.52 & $31 \%$ \\
Total & 11879522 & OK & 13418323.45 & OK \\
\hline \hline
\end{tabular}

\section{Perencanaan Struktur Primer}

\section{Penulangan Balok Induk}

Dari hasil perhitungan diperoleh balok dimensi 50/70 dengan kebutuhan tulangan tumpuan, lapangan dan geser yang dapat dilihat pada Tabel 7 dan Tabel 8.

Tabel 7.

Penulangan Tumpuan Balok Induk

\begin{tabular}{|c|c|c|c|c|c|c|}
\hline \multirow{2}{*}{$\begin{array}{l}\text { Kode } \\
\text { Balok } \\
\text { Induk } \\
\end{array}$} & \multirow{2}{*}{$\begin{array}{c}\text { Bentang } \\
(\mathrm{Lb}) \\
(\mathbf{m m})\end{array}$} & \multicolumn{2}{|c|}{$\begin{array}{c}\text { Tulangan } \\
\text { Lentur D25 }\end{array}$} & \multicolumn{2}{|c|}{ Sengkang } & \multirow{2}{*}{$\begin{array}{c}\text { Tulangan } \\
\text { Angkat }\end{array}$} \\
\hline & & Atas & Bawah & Plastis & Luar & \\
\hline BI1 & 6000 & 7 & 4 & Ø13-150 & $\varnothing 13-300$ & $2 \mathrm{D} 13$ \\
\hline $\mathrm{BI} 2$ & 4000 & 6 & 5 & Ø13-80 & $\varnothing 13-125$ & 2D13 \\
\hline $\mathrm{BI} 3$ & 2000 & 2 & 2 & Ø13-80 & Ø13-125 & 2D13 \\
\hline BI4 & 3000 & 4 & 4 & $\varnothing 13-80$ & Ø13-125 & 2D13 \\
\hline BI5 & 8000 & 7 & 4 & Ø13-100 & $\varnothing 13-300$ & 2D16 \\
\hline
\end{tabular}

Tabel 8.

Penulangan Lapangan Balok Induk

\begin{tabular}{|c|c|c|c|c|c|c|}
\hline \multirow{2}{*}{$\begin{array}{l}\text { Kode } \\
\text { Balok } \\
\text { Induk }\end{array}$} & \multirow{2}{*}{$\begin{array}{c}\text { Bentan } \\
\text { g (Lb) } \\
(\mathrm{mm})\end{array}$} & \multicolumn{2}{|c|}{$\begin{array}{c}\text { Tulangan } \\
\text { Lentur D25 }\end{array}$} & \multicolumn{2}{|c|}{ Sengkang } & \multirow{2}{*}{$\begin{array}{c}\text { Tulangan } \\
\text { Angkat }\end{array}$} \\
\hline & & Atas & Bawah & Plastis & Luar & \\
\hline BI1 & 6000 & 2 & 3 & $\varnothing 13-150$ & $\varnothing 13-300$ & 2D13 \\
\hline BI2 & 4000 & 2 & 4 & $\varnothing 13-80$ & $\varnothing 13-125$ & $2 \mathrm{D} 13$ \\
\hline $\mathrm{BI} 3$ & 2000 & 2 & 2 & $\varnothing 13-80$ & Ø13-125 & 2D13 \\
\hline BI4 & 3000 & 2 & 3 & $\varnothing 13-80$ & Ø13-125 & 2D13 \\
\hline BI5 & 8000 & 2 & 5 & Ø13-100 & $\varnothing 13-300$ & 2D16 \\
\hline
\end{tabular}

2. Penulangan Lentur Kolom $90 / 90$

Penulangan lentur kolom menggunakan program bantu spColumn sehingga didapatkan hasil sebagai berikut:

Rasio tulangan longitudinal $=1,76 \%$

Penulangan 28D25 (As $\left.=14280 \mathrm{~mm}^{2}\right)$

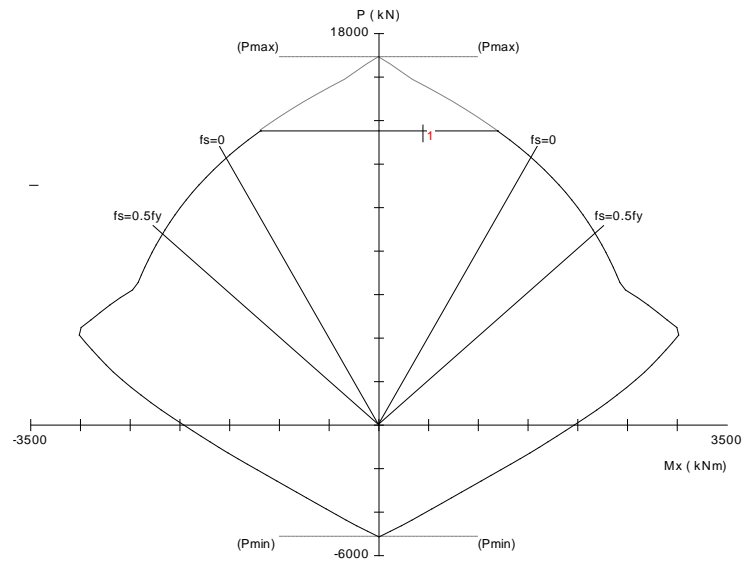

Gambar 9. Diagram interaksi aksial dengan momen kolom

3. Penulangan Dinding Geser

- Dinding geser horizontal $=2 \mathrm{D} 13-250 \mathrm{~mm}($ Arah X dan Y)

- Dinding geser vertikal $=2 \mathrm{D} 13-250 \mathrm{~mm}($ Arah $\mathrm{X}$ dan Y)

\section{E. Perencanaan Sambungan}

- Sambungan Balok dan Kolom Sesuai dengan SNI 2847:2013 pasal 11.8

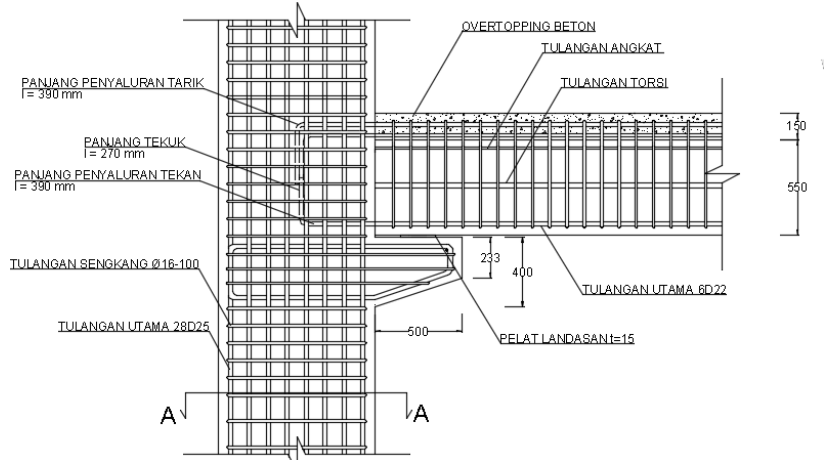

Gambar 10. Sambungan balok dan kolom

- Sambungan balok induk dan balok anak

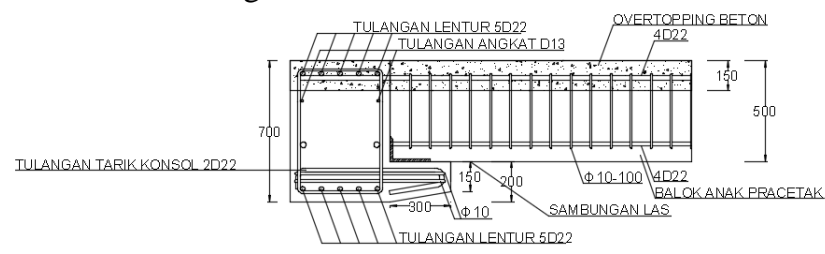

Gambar 11. Sambungan balok induk dan balok anak

- Sambungan balok dengan pelat

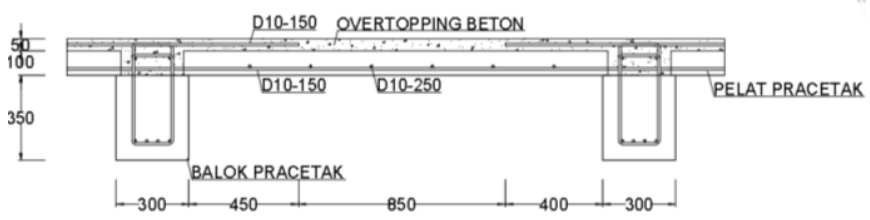

Gambar 12. Sambungan balok dan pelat

\section{F. Perencanaan Struktur Bawah}

1. Analisis Daya Dukung Tiang Pancang

Perhitungan daya dukung pondasi tiang pancang menggunakan metode Luciano Decourt

$$
\mathrm{Q}_{\mathrm{L}}=\mathrm{Q}_{\mathrm{P}}+\mathrm{Q}_{\mathrm{S}}
$$

Di mana:

$\mathrm{Q}_{\mathrm{L}} \quad=$ daya dukung tanah maksimum pada pondasi

$\mathrm{Q}_{\mathrm{P}} \quad=$ resistance ultimate di dasar pondasi

Qs = resistance ultimate akibat lekatan lateral

2. Perancangan Pondasi Tiang Pancang

Dari hasil perhitungan yang telah dilakukan diperoleh hasil sebagai berikut:

Pondasi kolom menggunakan Spun Pile sebanyak 4 buah dengan spesifikasi sebagai berikut:

$\begin{array}{ll}\text { Diameter outside }(D) & : 600 \mathrm{~mm} \\ \text { Thickness } & : 100 \mathrm{~mm} \\ \text { Bending momen crack } & : 196,4 \mathrm{kNm} \\ \text { Bending momen ultimate } & : 365 \mathrm{kNm} \\ \text { Allowable axial } & : 292 \mathrm{ton} \\ \text { Jarak antar tiang pancang } & : 1500 \mathrm{~mm} \\ \text { Jarak tiang pancang ke tepi } & : 600 \mathrm{~mm}\end{array}$

\section{KESIMPULAN}

A. Kesimpulan

Berdasarkan perancangan struktur yang dilakukan dalam penyusunan Penelitian "Modifikasi Perencanaan Rumah Sakit Umum Daerah (RSUD) Koja Jakarta dengan Metode Pracetak" maka dapat disimpulkan diantaranya sebagai berikut:

1. Berdasarkan perancangan dimensi balok dan pelat yang mengacu pada SNI 2847:2013 pasal 9.5.2, yaitu ketentuan tebal minimum balok non prategang satu arah, juga 
perhitungan dimensi kolom, didapatkan hasil modifikasi sebagai berikut:

a. Struktur Sekunder

- Dimensi balok anak

$$
=30 / 50 \mathrm{~cm}
$$

- Dimensi balok bordes tangga

$=50 / 70 \mathrm{~cm}$

- Dimensi balok bordes ramp

$=35 / 50 \mathrm{~cm}$

- Dimensi penggantung lift

$=30 / 50 \mathrm{~cm}$

- Dimensi penumpu lift

$=30 / 50 \mathrm{~cm}$

- Tebal pelat

$=15 \mathrm{~cm}$

b. Struktur Primer

- Dimensi balok induk $\quad=50 / 70 \mathrm{~cm}$

- Dimensi kolom $\quad=90 / 90 \mathrm{~cm}$

- Dimensi pilecap $=2,7 \times 2,7 \times 1,1 \mathrm{~m}$

- Tiang pancang $=D 60, H=21 \mathrm{~m}$

- Tebal shearwall $\quad=40 \mathrm{~cm}$

2. Komponen pracetak disambung dengan menggunakan sambungan basah (cor di tempat) dan konsol pendek agar bangunan tersebut menjadi bangunan pracetak yang monolit. Ukuran konsol pendek pada kolom adalah $500 \times$ $400 \mathrm{~mm}$ dan konsol pendek pada balok induk adalah $300 / 185 \mathrm{~mm}$

3. Detailing sambungan pracetak dirancang bersifat monolit antar elemennya dengan tulangan - tulangan dan shear connector yang muncul dari setiap elemen pracetak untuk menyatukan dengan elemen cor di tempat. Sambungan didesain sesuai dengan ketentuan yang berlaku yang mengacu pada SNI 2847:2013

B. Saran

Berdasarkan analisis selama proses penyusunan penelitian ini, beberapa saran yang penulis dapat sampaikan adalah sebagai berikut:

1. Pengerjaan sambungan antar elemen beton pracetak harus benar - benar diawasi agar gaya - gaya dari elemen beton pracetak dapat tersalurkan dengan baik, juga agar gedung menjadi monolit.

2. Sambungan pracetak lebih baik dibuat seminimal mungkin, agar elemen - elemen beton pracetak menjadi seragam sehingga memudahkan pembuatan elemen elemen beton pracetak tersebut.

3. Masih banyak hal yang memerlukan penelitian lebih lanjut pada pengerjaan beton pracetak agar meningkatkan efisiensi pengerjaan, terutama pada sambungan elemen elemen beton pracetak.

\section{DAFTAR PUSTAKA}

[1] Abduh, Muhammad. 2007. Inovasi Teknologi dan Sistem Beton Pracetak di Indonesia: Sebuah Analisis Rantai Nilai. Seminar dan Pameran HAKI 2007 - "KONSTRUKSI TAHAN GEMPA DI INDONESIA". Jakarta.

[2] Toscas, James G. 2014. Designing with Precast and Prestressed. Precast/Prestressed Concrete Institute (PCI).

[3] Nurjannah, Siti Aisyah. 2011. Perkembangan Sistem Struktur Beton Pracetak sebagai Alternatif pada Teknologi Konstruksi Indonesia yang Mendukung Efisiensi Energi serta Ramah Lingkungan. Prosiding Seminar Nasional AVoER ke-3 Palembang, 26-27 Oktober 2011. Universitas Sriwijaya, Palembang.

[4] Ervianto, Wulfram I. 2006. Eksplorasi Teknologi dalam Proyek Konstruksi: Beton Pracetak \& Bekisting. Yogyakarta. PENERBIT ANDI Yogyakarta.

[5] Badan Standardisasi Nasional. 2013. SNI 03-2847-2013 Persyaratan Beton Struktural untuk Bangunan Gedung. Jakarta: Badan Standardisasi Nasional.

[6] Badan Standardisasi Nasional. 2012. SNI 03-1726-2012 Tata Cara Perencanaan Ketahanan Gempa untuk Bangunan Gedung. Jakarta: Badan Standardisasi Nasional. 